\title{
A Soft- Tissue Injury Diagnosis in Knee Replacement Patients cannot be made without a Plain Radiograph
}

\author{
Rute Castelhano ${ }^{1}$, Sunny Deo ${ }^{1}$
}

Learning Point of the Article:

Posterior dislocations may cause localiszed pain and therefore be mistaken for other pathology, including tendon strains.

\section{Abstract}

Introduction: Introduction: The design of some knee replacements includes the use of a mobile polyethylene bearing which can potentially dislocate away from the main bearing surfaces. This is particularly the case in unicompartmental or partial knee replacements (UKRs), and the most widely used UKR currently has this feature. Bearing dislocations are typically very painful and disabling, but not always, as in the case we present.

Case Report: We report the case of a patient presenting at a 1 -year follow- up following a mobile bearing UKR. At this consultation, the patient reported a smooth initial recovery but with on-going pain and swelling in the posterior aspect of his knee for 3 months, diagnosed as a soft- tissue strain.

Results: Radiographs at 1 year follow-up appointment showed that the polyethylene insert was dislocated posteriorly towards the popliteal fossa with metal components in direct contact. At revision surgery, this was confirmed as a chronic dislocation with severe metallosis requiring revision to a total knee replacement.

Conclusion: We report a case of a posterior dislocation of a mobile polyethylene bearing of a partial / unicompartmental knee replacement UKR with delayed definitive treatment due to mis-diagnosis at the time of onset of symptoms and signs. The key lesson is that plain radiographs should be obtained promptly for any local issue in knee replacement patients.

Keywords: Unicompartmental knee replacement, metallosis, mobile bearing dislocation, soft tissue injuries.

\section{Introduction}

Mobile polyethylene bearings have been used in the Oxfordtype unicompartmental arthroplasty for over 40 years (Biomet, Bridgend, South Wales) [1]. The mobile bearings allow for gliding and rotation at the level of the femorotibial joint with increased contact area, reduction in contact stresses with minimization of polyethylene wear $[1,2,3,4,5]$. Mobile bearing implants have an outstanding long-term survival comparable to total and fixed-bearing unicompartmental or partial knee replacements (UKRs) $[6,7]$, and are the most widely used UKR used in the United Kingdom (UK) [6]. Another advantage is the capacity for the mobile bearing to accommodate errors in the rotational positioning of the tibial

\section{component $[1,2,3]$.}

UKRs were introduced in the 1950s by McKeever and MacIntosh. They are surgical procedures used to replace damaged bone and cartilage in one compartment of the knee. The majority of UKRs currently used in the UK have a mobile polyethylene bearing that is mobile within the joint, between metal components, which are bonded to the femur and tibia (Fig. 1-3). One of the known complications of mobile bearings is dislocation and subluxation, which has a reported occurrence rate in UKR of $0.5-5 \%[8,9,10]$, with the majority of dislocations being anterior or lateral $[8,9,10]$.

This case report presents an uncommon case of a posterior dislocation of the mobile polyethylene bearing toward the

\begin{tabular}{|c|c|}
\hline & Author's Photo Gallery \\
\hline \multicolumn{2}{|l|}{ Access this article online } \\
\hline $\begin{array}{c}\text { Website: } \\
\text { www.jocr.co.in }\end{array}$ & Dr. Rute Castelhano \\
\hline $\begin{array}{c}\text { DOI: } \\
10.13107 / \text { jocr.2021.v11.i04.2150 }\end{array}$ & $\begin{array}{l}\text { 'Department of Trauma and Orthopaedics, The Great Western Hospitals NHS Foundation Trust, Swindon, United Kingdom. } \\
\text { Address of Correspondence: } \\
\text { Dr. Rute Castelhano, } \\
\text { Department of Trauma and Orthopaedics, The Great Western Hospitals NHS Foundation Trust, Swindon, United Kingdom. } \\
\text { E-mail: rute.castelhano@nhs.net }\end{array}$ \\
\hline
\end{tabular}

Journal of Orthopaedic Case Reports | pISSN 2250-0685 | eISSN 2321-3817 | Available on www.jocr.co.in | doi:10.13107/jocr.2021.v11.i04.2150 This is an Open Access article distributed under the terms of the Creative Commons Attribution Non-Commercial License (http://creativecommons.org/licenses/by-nc/3.0) which permits unrestricted non-commercial use, distribution, and reproduction in any medium, provided the original work is properly cited. 


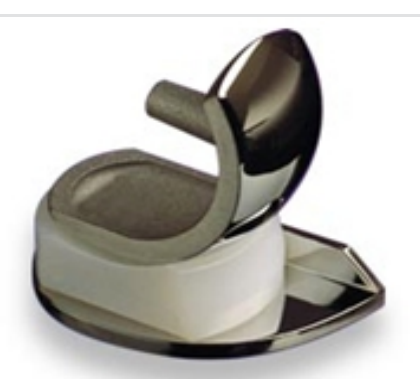

Figure 1: Normal appearance of medial unicompartmental knee replacement.

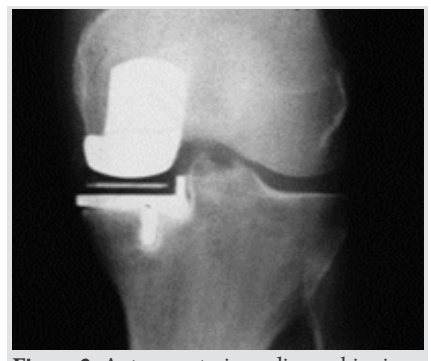

Figure 2: Anteroposterior radiographic views of a normally positioned unicompartmental knee replacement.

popliteal fossa and a delay in definitive management.

\section{Case Report}

A 62-year-old man attended his routine 1 year follow-up consultation following an uncomplicated UKR with a mobile bearing. During this appointment, the patient reported an uneventful initial recovery followed by an on-going pain and swelling in the posterior aspect of his knee, which started around 9 months after his surgery. He noted that the symptoms had evolved to a more constant background ache with consistent activity related pain alongside more stiffness over the last month.

The pain triggered his attendance to a community hospital on multiple occasions. The patient reported no specific history of trauma, but he remembers tripping while walking around the time of onset of recurrent symptoms. He complained of variable pain at the back of his knee which would ease, but never fully resolved. The main area of discomfort was around the medial hamstring tendons. At every attendance to the community hospital, he was assessed and reassured that this was most likely to be a hamstring strain and consequently, discharged with analgesia without any requirement of further investigation or discussion with our arthroplasty department.

At the 1 year follow-up appointment, radiographs (Fig. 4) were obtained which indicated that the polyethylene inserted was in fact dislocated posteriorly toward the popliteal fossa, into soft tissues adjacent to the neurovascular bundle, with consequent direct contact of metal components.

Clinical examination revealed a moderately swollen knee with a minimal effusion, with the affected limb noted to be in a greater varus alignment at the knee compared to the other leg. The range of motion was $10-125^{\circ}$ with no noted major instability, and the varus was not fully correctable. There was moderate tenderness in the medial proximal tibia and distal femur as well as tenderness and focal swelling in the medial aspect of his popliteal fossa and medial hamstring tendon area.

The patient underwent a surgical exploration which revealed that both the femoral and tibial components were severely abraded, with consequent severe metallosis within the

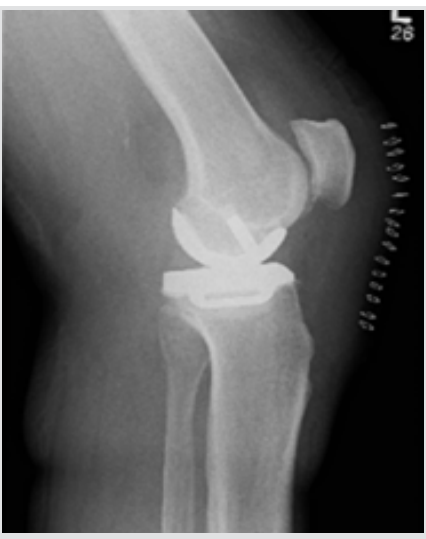

Figure 3: Lateral radiographic views of a normally positioned unicompartmental knee replacement.

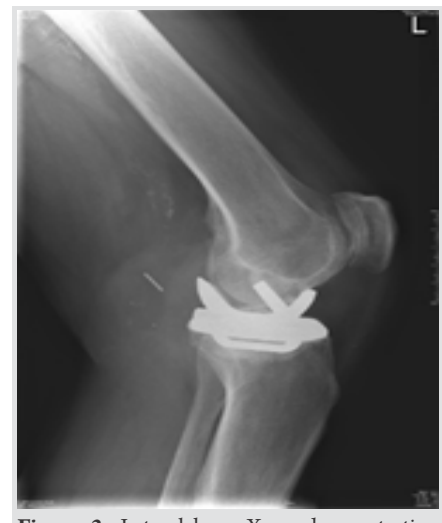

Figure 3: Lateral knee X-ray demonstrating contact between metal components, with posterior dislocation of tibial polyethylene bearing component.

synovium. The polyethylene insert was encapsulated in thick fibrous tissue in the posterior soft tissues at the back of the knee which caused a difficult dissection close to the popliteal neurovascular structures. The initial incision had to be extended and UKR implants were removed, due to the degree of abrasive damage, to allow for a radical synovectomy and limited bone resection to remove the metallosis and for safe removal of the mobile bearing and its pseudocapsule. A total knee replacement (TKR) was undertaken with the patient mobilizing in a standard fashion, after which, they were discharged a 3 days later, without noted perioperative problem or complication. The patient went on to make a smooth recovery and was reviewed again at 1 and 5 years post-revision surgery.

\section{Discussion}

The mobile bearing design aim to achieve optimal congruence to achieve with knee kinematics as close to normal as possible, allowing for gliding and rotational self-adjustment, whilst minimizing polyethylene wear [11]. UKRs have an outstanding long-term functional outcome with a very low occurrence of implant failure $[4,12]$. It is suitable for patients with single compartment tibiofemoral wear, younger age, and higher functional demand [13].

However, mobile bearing may have some complications such as bearing dislocations, bearing breakage, and polyethylene wear [6]. Mobile bearing dislocation can be a complication even though the rate of incidence is low $[6+$ the others from the intro!], requires immediate reduction as delay will lead to abrasive metal on metal wear and metallosis $[5,6,7,8,9,10,11$, 12].

The treatment options for bearing dislocations include closed reduction, open exploration, and bearing exchange or revision to a TKR [14]. Closed reduction is rarely performed as its unlikely to address the underlying cause and is generally only feasible if there is a subluxation rather than full dislocation, as 
the bearing often ends up away from the tibiofemoral articulation. The open reduction, removal of dislocated bearing, and bearing exchange are the preferred surgical option as it is minimally invasive, allows for the bearing size to be retrialed, and gives the surgeon an opportunity to assess the stability of this construct. In general, conversion to TKR is the final treatment option.

Our clinical experience of bearing dislocation, while uncommon, is that the patients will tend to present with an acute onset of pain, often after a twisting or deep flexion maneuver, often with an associated pop or clunk that leaves them in severe pain, with marked restriction of movement and often inability to weight-bear [12]. Symptoms are similar in pattern and description to an acute locked knee. Clinical signs also often mimic an acute locked knee with moderate effusion, varus deformity, and marked joint line tenderness. This presentation did not occur in our patient and thus represents an atypical presentation.

This case demonstrated that the dislocation of the mobile bearing occurred within the 1st year, with a minimally traumatic event, a slight mis-step while walking. Mild and subtle signs, mainly at the back of his knee and close to the medial hamstring tendons, made the diagnosis more difficult and less suspicious of a mobile bearing dislocation. Our patient attended a community hospital on three occasions, but radiographs were not requested or suggested to assess the knee and the mobile bearing implanted. Instead the patient was reassured that his symptoms were likely due to a hamstring strain.

A replaced joint with non-settling symptoms, even if subtle, should raise concerns and be investigated with imaging before discharging the patient with reassurance.

Our case demonstrates that early recognition of this condition is crucial to prevent or at least diminish joint and implant damage. Diagnostic delay may result in significant consequences for the patient, which almost certainly led to early revision of a UKR to TKR, rather than exploration and bearing exchange.

\section{Conclusion}

A high proportion of UKRs has a mobile bearing, which has a known, low risk of dislocation.

If bearing dislocations present without major pain or mechanical symptoms, they can be mistaken for other pathologies, including tendon strains.

Clinicians should have awareness of these two key facts and have a low threshold for requesting suitable imaging.

A neglected bearing dislocation can lead to severe abrasive wear which likely necessitate full revision.

\section{Clinical Message}

Clinicians should have a low threshold for requesting appropriate imaging, a set of standard plain radiographs will usually be sufficient in arthroplasty patients in diagnosing implant-related problems and should be cautious when diagnosing benign soft-tissue problems in the absence of imaging.

\section{References}

1. de Araújo Barros Cobra HA, da Palma IM. Mobile tibial polyethylene bearing in the total knee arthroplasty. Rev Bras Ortop 2015;44:475-8.

2. Dennis DA, Komistek RD, Mahfouz MR, Outten JT, Sharma A. Mobile-bearing total knee arthroplasty. Do the polyethylene bearings rotate? Clin Orthop Relat Res 2005;440:88-95.

3. Scott RD. Total knee arthroplasty. In: Mobile Versus Fixed Bearings in Total Knee Arthroplasty. Philadelphia, PA: Saunders; 2006.p. 16-9.

4. Goodfellow J, O'Connor J. The mechanics of the knee and prosthesis design.J Bone Joint Surg 1978;60B:358-69.

5. Kwon OR, Kang KT, Son J, Kwon SK, Jo SB, Kwon SK, Jo SB, Suh DS, et al. Biomechanical comparison of fixed- and mobile-bearing for unicomparmental knee arthroplasty using finite element analysis. J Orthop Res 2013;32:33845 .
6. Callaghan JJ. Mobile-bearing knee replacement: Clinical results. A review of the literature. Clin Orthop Relat Res 2001;392:221-5.

7. Pandit H, Hamilton TW, Jenkins C, Mellon SJ, Dodd CA, Murray DW. The clinical outcome of minimally invasive Phase 3 Oxford unicompartmental knee arthroplasty a 15year follow-up of 1000 UKAs. J Bone Joint Surg Br 2015;97B:1493-500.

8. Pandit H, Jenkins C, Beard DJ, Price AJ, Gill HS, Dodd CA, et al. Mobile bearing dislocation in lateral unicompartmental knee replacement. Knee 2010;17:392-7.

9. Kim SJ, Postigo R, Koo S, Kim JH. Causes of revision following Oxford phase 3 unicompartmental knee arthroplasty. Knee Surg Sports Traumatol Arthrosc 2014;22:1895-901.

10. Singh VK, Apsingi S, Balakrishnan S, Manjure S. Posterior dislocation of meniscal bearing insert in mobile bearing 
unicompartmental knee arthroplasty mimicking a Baker cyst.J Arthroplasty 2012;27:494.e13.

11. Most E, Li G, Schule S, Sultan P, Park SE, Zayontz S, Rubash HE. The kinematics of fixed- and mobile-bearing total knee arhroplasty. Clin Orthop Relat Res 2003;416:197207.

12. Jonas SC, Shah R, Mitra A, Deo SD. 5-year cost/benefit analysis of revision of failed unicompartmental knee replacements (UKRs): Not "just" a primary total knee replacement (TKR). Knee 2014;21:840-2.
13. Walker T, Streit J, Gotterbarm T, Bruckner T, Merle C, Streit MR. Sports, physical activity and patient-reported outcomes after medial unicompartmental knee arthroplasty in young patients. J Arthroplasty 2015;30:1911-6.

14. Kim SG, Kim HG, Lee SY, Lim HC, Bae JH. Redislocation after bearing exchange for the treatment of mobile bearing dislocation in medial unicompartmental knee arthroplasty. Knee Surg Relat Res 2018;30:234-40.

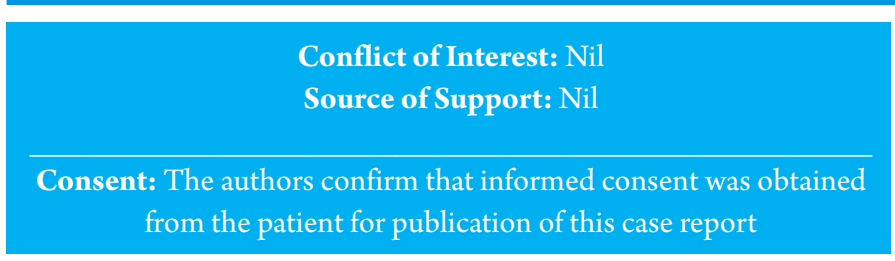

How to Cite this Article

Castelhano R, Deo S. A Soft-Tissue Injury Diagnosis in Knee Replacement Patients cannot be made without a Plain Radiograph. Journal of Orthopaedic Case Reports 2021 April;11(4): 52-55 